\title{
Pengenalan STEM (Science, Technology, Engineering, and Mathematics) dan Pengembangan Rancangan Pembelajarannya untuk Merintis Pembelajaran Kimia dengan Sistem SKS di Kota Madiun
}

\author{
Nur Candra Eka Setiawan*, Sutrisno, Munzil, Danar \\ Jurusan Kimia, FMIPA Universitas Negeri Malang, JI. Cakrawala No.5, Sumbersari, Kec. \\ Lowokwaru, Kota Malang, Jawa Timur 65145, Indonesia \\ Email Korespondensi: nur.setiawan.fmipa@um.ac.id
}

\section{Diterima: September 2020; Revisi: Oktober 2020; Diterbitkan: November 2020}

\begin{abstract}
Abstrak
Tujuan dari kegitan ini adalah untuk pengenalan dan pengembangan rancangan pembelajaran STEM (Science, Technology, Engineering, and Mathematics) dalam meningkatkan Kompetensi Guru Kimia SMA dan SMK di Kota Madiun. Mitra dalam kegitan ini adalah guru kimia yang tergabung dalam MGMP kimia SMA dan SMK di Kota Madiun. Kegiatan diikuti oleh 21 orang guru. Metode dalam kegitan ini adalah trasfer of knowledge melalui kegitan workshop. Hasil kegiatan pengabdian kepada masyarakat ini adalah: (1) mampu mencari solusi atas permasalahan yang dihadapi guru kimia di Kota Madiun, ditunjukkan oleh peningkatan capaian pemahaman melalui diklat sebesar $26,36 \%$ (dilihat dari tes awal dan tes akhir), dan (2) Pemahaman guru terhadap STEM sebesar 83,81\%. Harapan peserta dan mitra kolaborasi (MGMP Kimia Kota Madiun), kegiatan semacam ini dapat secara berkesinambungan, terutama menyusun dan mengembangkan Desain Pembelajaran Berbasis STEM pada materi kimia di Sekolah Menengah dan implementasi pembelajarannya.
\end{abstract}

Kata Kunci: STEM; Rancangan Pembelajaran Kimia; Sistem SKS

\section{Introduction to STEM (Science, Technology, Engineering, and Mathematics) and the Development of Learning Designs to Pioneering Chemistry Learning with the Credit System in Madiun City}

\begin{abstract}
The purpose of this activity is to introduce and develop STEM (Science, Technology, Engineering, and Mathematics) learning designs in improving the Competence of High School and Vocational School Chemistry Teachers in Madiun City. Partners in this activity are chemistry teachers who are members of the High School and Vocational High School Chemistry MGMP in Madiun City. The activity was attended by 21 teachers. The method in this activity is the transfer of knowledge through workshop activities. The results of this community service activity are: (1) being able to find solutions to problems faced by chemistry teachers in Madiun City, indicated by an increase in understanding achievement through training by $26.36 \%$ (seen from the initial test and final test), and (2) Teachers' understanding of STEM was $83.81 \%$. The hope of the participants and collaboration partners (MGMP Kimia Kota Madiun), this kind of activity can be sustainable, especially compiling and developing STEM-Based Learning Designs on chemistry materials in secondary schools and the implementation of learning.
\end{abstract}

Keywords: STEM; Chemistry Learning Design; Credit System

How to Cite: Setiawan, N., Sutrisno, S., Munzil, M., \& Danar, D. (2020). Pengenalan STEM (Science, Technology, Engineering, and Mathematics) dan Pengembangan Rancangan Pembelajarannya untuk Merintis Pembelajaran Kimia dengan Sistem SKS di Kota Madiun. Lumbung Inovasi: Jurnal Pengabdian kepada Masyarakat, 5(2), 56-64. doi:https://doi.org/10.36312/linov.v5i2.465 


\section{PENDAHULUAN}

STEM merupakan akronim dari Science, Technology, Engineering, Mathematics. Istilah STEM pertama kali diluncurkan oleh National Science Foundation AS pada tahun 1990-an dengan nama SMET namun istilah tersebut kurang disetujui oleh beberapa pihak yang kemudian diubah menjadi sebagai tema gerakan reformasi pendidikan dalam keempat bidang disiplin ilmu tersebut untuk menumbuhkan angkatan kerja dibidang STEM, serta mengembangkan warga negara yang menguasai ilmu STEM (STEM literate), serta meningkatnya daya sasing global Amerika Serikat (AS) dalam inovasi iptek (Mulyani, 2019). Pendekatan dari keempat bidang ilmu tersebut merupakan kolaborasi bidang ilmu yang serasi antar masalah yang terjadi di dunia nyata (Matanluk et al., 2013; Torlakson, 2014).

Pendekatan model pembelajaran STEM dalam bidang pendidikan bertujuan untuk mempersiapkan peserta didik supaya dapat bersaing dan siap untuk bekerja sesuai bidang keahliannya, peneitian yang dilakukan oleh lembaga penelitian Hannover Research (2011) menunjukkan bahwa tujuan utama pembelajaran STEM adalah usaha untuk menunjukkan pengetahuan yang bersifat holistik antara subjek STEM. Tujuan dari pembelajaran menggunakan pendekatan STEM cocok diterapkan pada pembelajaran sekolah menengah kejuruan yang subjek dalam pembelajarannya membutuhkan pengetahuan yang komplek.

Terkait dengan STEM literasi, terdapat empat dimensi yang terintegrasi untuk mendukung kompetensi siswa di sekolah yaitu sains, teknologi, teknik, dan matematika (Rustaman, 2015). Lebih lanjut diungkapkan bahwa sebagaimana literasi sains melibatkan empat komponen (pengetahuan konten, proses, konteks dan attitude sebagai tiga dimensi terhadap kompetensi (Kumano \& Goto, 2015), maka STEM literasi juga melibatkan cross cutting concepts, core ideas of four discipline, scientific and engineering practice sebagai konteksnya untuk mendukung kompetensi dalam STEM.

Tabel 1. Literasi Empat Disiplin IImu STEM (Ardianto et al., 2019)

\section{Disiplin IImu STEM Literasi}

\begin{tabular}{|c|c|}
\hline Science & $\begin{array}{l}\text { Kemampuan dalam menggunakan pengetahuan ilmiah dalam } \\
\text { memahami dunia alam serta kemampuan untuk berpartisipasi } \\
\text { dalam mengambil keputusan untuk mempengaruhinya. }\end{array}$ \\
\hline Technology & $\begin{array}{l}\text { Pengetahuan bagaimana menggunakan teknologi baru } \\
\text { bagaimana teknologi baru dikembangkan, dan memiliki } \\
\text { kemampuan untuk bagaiman teknologi baru mempengaruhi } \\
\text { individu, masyarakat, bangsa, dan negara. }\end{array}$ \\
\hline Engineering & $\begin{array}{l}\text { Pemahaman tentang bagaimana teknologi dapat dikembangkan } \\
\text { melalui proses reakayasa/desain menggunakan tema pelajaran } \\
\text { berbasis proyek dengan cara mengintregasikan dari bebrapa } \\
\text { mata pelajaran. }\end{array}$ \\
\hline Mathematic & $\begin{array}{l}\text { kemampuan dalam dalam menganalisis alsan dan } \\
\text { mengkomunikasikan ide secara efektif dan dari cara bersikap, } \\
\text { merumuskan, dan menafsirkan solusi untuk maslah matematika } \\
\text { dalam menerapkan berbagai situasi berbeda. }\end{array}$ \\
\hline
\end{tabular}

Pelaksanaan pembelajaran STEM pendidik harus dapat mengintregasikan pengetahuan, ketrampilan dan nilai ilmu pengetahuan, teknologi, rekayasa, dan matematika untuk dapat menyelesaikan sebuah masalah yang berhubungan dengan pembelajaran dalam konteks kehidupan sehari-hari. Ciri-ciri pembelajaran STEM dijabarkan pada Gambar 1. 


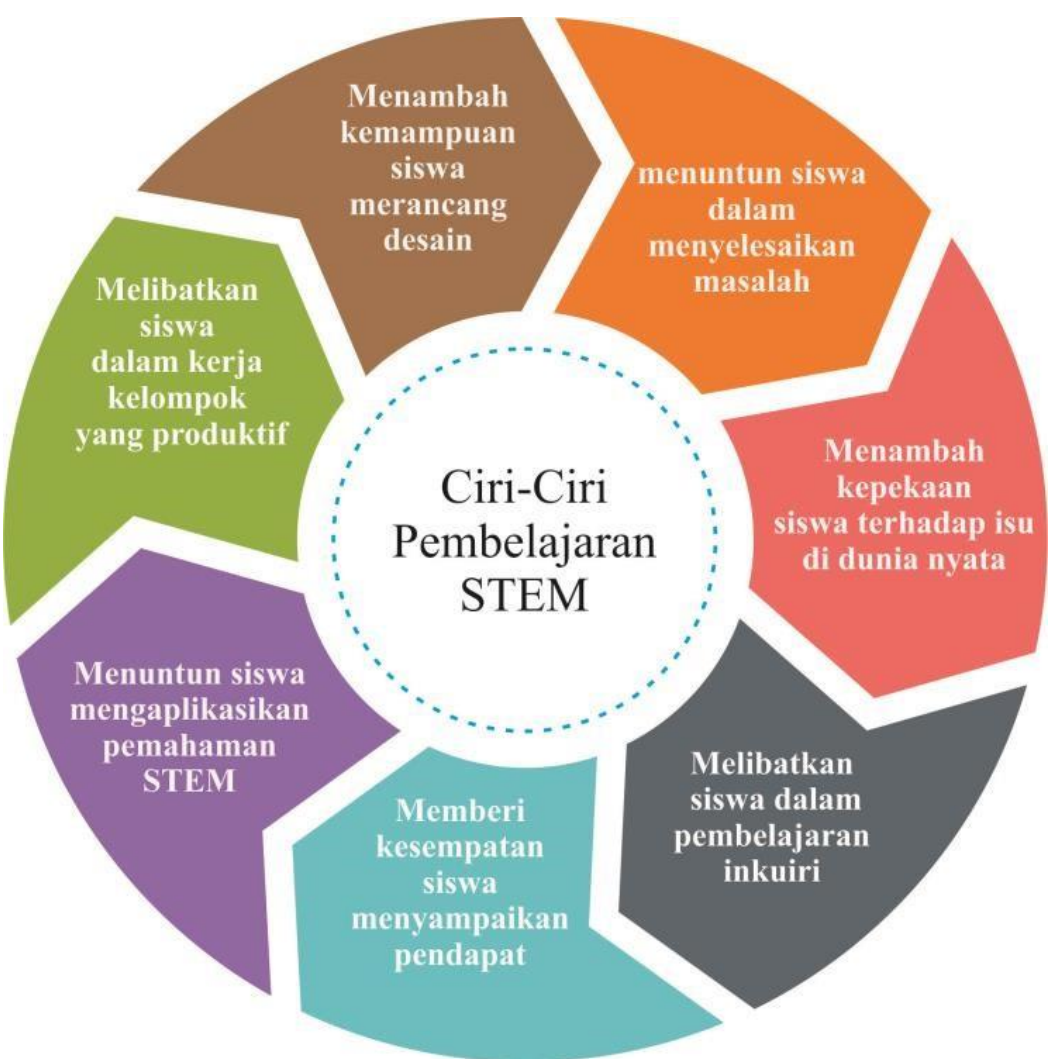

\section{Gambar 1. Ciri-Ciri Pembelajaran STEM}

Pendidikan STEM merupakan pendidikan yang mengintregasikan ilmu pengetahuan, teknologi, rekayasa dan matematika secara formal berdasarkan kurikulum. Pendidikan STEM juga dapat dilaksanakan secara non formal melalui aktivitas nonakademik dan nonkurikulum. Pendidikan STEM diharapkan membentuk sumber daya manusia yang memiliki keahlian yang tinggi sesuai bidangnya sehingga dapat memberikan inovasi baru.

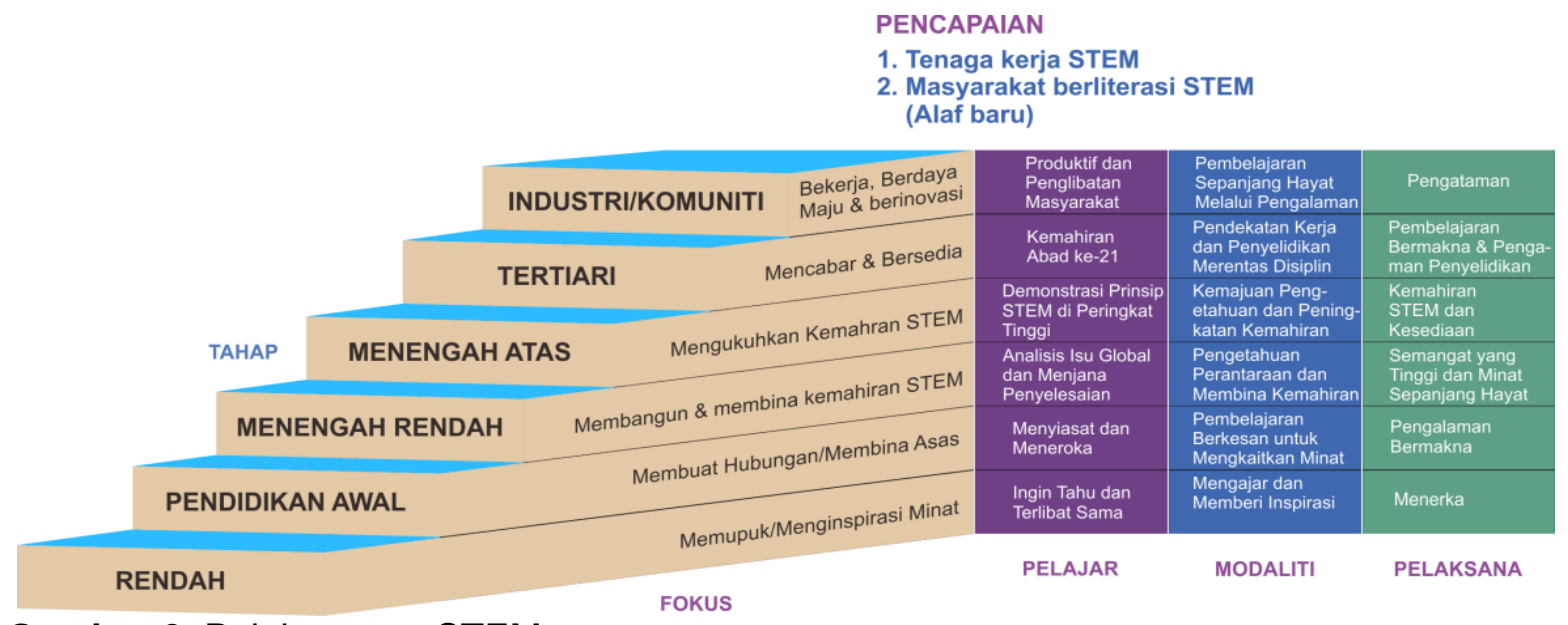

\section{Gambar 2. Pelaksanaan STEM}

Berdasarkan Gambar 2, fokus pendidikan STEM di setiap tingkatan pendidikan memiliki perbedaan yang disesuaikan dengan kemampuan berpikir kognitif. Fokus pendidikan STEM pada tingkat pendidikan awal adalah mencetuskan dan memupuk minat peserta didik melalui aktivitas-aktivitas yang dapat merangsang rasa ingin tahu peserta didik. Langkah awal ini memberikan pembelajaran berbasis masalah terstruktur dan berkaitan dengan dunia nyata yang menghubungkan keempat aspek STEM.

Uraian di atas menunjukkan bahwa pembelajaran dengan STEM pada matapelajaran kimia menjadi sangat penting untuk mengembangkan kemampuan kognitif, apektif, dan 
psikomotorik siswa. Hasil penerapan media pembelajaran yang dilakukan Susanti (2018) menunjukkan adanya perbedaan hasil pencapaian kompetensi yang cukup signifikan (kognitif, afektif, dan psikomotor) antara siswa yang mengikuti pembelajaran reaksi redoks dengan pembelajaran STEM dan siswa yang mengikuti pembelajaran dengan metode konvensional. Rata-rata nilai kognitif siswa setelah pembelajaran berlangsung adalah 7,8 pada kelas eksperimen dan 7,4 (0-10) pada kelas kontrol. Sedangkan nilai afektif siswa pada kelas eksperimen memperoleh rata-rata nilai 3,32 dan siswa kelas kontrol memperoleh ratarata nilai 3,09 (0-4). Lebih lanjut, Agustina et al., (2017) menemukan bahwa ada peningkatan control of variable siswa setelah diterapkan pembelajaran berbasis STEM memiliki $n$-gain sebesar 0,45 dalam katagori sedang.

Penerapan kurikulum 2013 di sekolah mengisyarakatkan bahwa proses pembelajaran harus dapat memperkaya pengalaman belajar siswa dengan menggunakan pendekatan berbasis saintifik. Untuk merealisasikannya guru perlu memahami prinsip-prinsip pedagogik yang salah satunya adalah Desain Belajar. Salah satu sumber belajar di era milenial dan menjadi cukup populer adalah STEM (Science, Technology, Engineering, and Mathematics). Akan tetapi terdapat berapa permasalahan antara lain 1) guru belum memahaminya secara holistik dan komprehensif tentang pengembangan pembelajaran kimia berbasis STEM, 2) guru masih mengalami kesulitan dalam memahami dan menyusun-mengembangkan Desain Pembelajaran Berbasis STEM untuk Inovasi Pembelajaran Kimia di SMA, 3) guru belum dapat memaknai apa yang dimaksud dengan Desain Pembelajaran Berbasis STEM untuk pembelajaran kimia serta penerapannya di kelasnya, (2) guru belum mempunyai pengalaman bahkan belum pernah menyusun dan mengembangkan Desain Pembelajaran Berbasis STEM.

Kondisi ini menjadi dasar dilakukan Program Kemitraan Masyarakat (PKM) dengan tujuan pengenalan dan pengembangan rancangan pembelajaran STEM (Science, Technology, Engineering, and Mathematics) dalam meningkatkan Kompetensi Guru Kimia SMA dan SMK di Kota Madiun.

\section{METODE PELAKSANAAN}

Pelaksanaan pengabdian dilaksanakan dengan metode trasfer of knowledge dengan tahapan-tahan kegitan antara lain persiapan, pelaksanaan dan evaluasi. Mitra dalam kegitan ini adalah guru kimia yang tergabung dalam MGMP kimia SMA dan SMK di Kota Madiun. Kegiatan diikuti oleh 21 orang guru.

Pelaksanaan kegiatan dalam rangka pengabdian masyarakat ini adalah tatap-muka (offline) dan online. Kegiatan offline ini dalam bentuk Pemaparan atau "Kuliah" dan Workshop. "Kuliah" atau kegiatan paparan konsep dilakukan secara klasikal dan atau kelompok dengan metode ceramah (ekspositori), diskusi, tanya-jawab, dan workshop dengan agenda acara:

1. Paparan konsep-konsep "Ragam Sumber Balajar" untuk pembelajaran kimia dan penguatan materi atau konsep kimia secara ekspositori;

2. Diskusi dan tanya-jawab sebagai respon dan hasil pemaparan secara konseptualkomprehensif untuk pembelajaran kimia berbasis konflik kognitif;

3. Workshop dan Pendampingan Penyusunan dan Pengembangan Pembelajaran berbasis STEM (saat tatap muka, Pertemuan tahap 1 dan tahap 2)

Pelaksanaan PKM secara online (via WA dan/atau Email) yakni bimbingan dan pendampingan lanjutan, hal ini bertujuan untuk mempermudah proses guru untuk bertaya dan berdiskusi pada saat diluar jam workshop.

Bahan Ajar atau Bahan Paparan meliputi:

1. Tentang STEM dalam Pembelajaran IImu Kimia: (a) Definisi dan Ciri-ciri atau Karakteristiknya (b) Tujuan dan Manfaat, dan (c) Sistematika dan Format

2. Telaah Silabus Kimia SMA Kurikulum 2013 Revisi 2017

3. Identifikasi Materi atau Topik menurut Silabus Kimia SMA Kurikulum 2013 Revisi 2017 untuk Pengembangan Pembelajaran Kimia berbasis STEM

4. Desain STEM untuk Pembelajaran Kimia di SMA Instrumen Asesmen dan Angket (Kuesioner) meliputi:

1. Instrumen Asesmen Penguasaan/Pemahaman Konsep: Pembelajaran Kimia berbasis STEM, dengan konten meliputi 

a. Definisi dan Ciri-ciri atau Karakteristiknya
b. Tujuan dan Manfaat
c. Sistematika dan Format

2. Angket atau Kuesioner tentang:

a. Respon dan Persepsi peserta terhadap Program dan Kegiatan Pengabdian kepada Masyarakat ini, dan

b. Refleksi Diri terhadap Proses dan Hasil Kegiatan dalam Program Kemitraan ini dan Rencana ke depan dari masing-masing peserta dalam rangka Perbaikan/ImproviasiInovasi Pembelajaran Kimia di klasnya.

\section{HASIL DAN PEMBAHASAN}

Hasil yang dicapai melalui langkah-langkah kegiatan pengabdian kepada masyarkat ini dideskripsikan sebagai berikut.

\section{Hasil yang dicapai pada Tahap Persiapan}

Sesuai dengan rancangan yang dilakukan, kegiatan dan hasil-hasil yang diperoleh padaTahap Persiapan ini adalah sebagai berikut:

1. Penyusunan Rencana Kegiatan dengan Mitra

Penyusunan rencana kegiatan (identifikasi kebutuhan, metode implementasi, dan waktu pelaksanaan untuk tatap muka kegiatan pendidikan/pelatihan dan workshop) didiskusikan dan disepakati bersama antara Tim Kegiatan dengan Tim Mitra, yang dalam hal ini diwakili oleh Ketua MGMP Kimia SMA Kota Madiun. Kegiatan ini berlangsung pada 8 Agustus 2020 dengan komunikasi via Whatsapp dan telepon.

2. Penyusunan Angket untuk Menjaring Tingkat Pemahaman tentang Modul

Untuk memperoleh gambaran tentang pemahaman STEM maka dilakukan penjaringan penguasaan atau pemahaman melalui tes dengan Instrumen Asesmen. Angket berisi pertanyaan-pertanyaan tentang konsep-konsep STEM. Di samping itu, pemetaan dan gambaran STEM yang diidentifikasi melalui angket, juga dilakukan berdasarkan hasil diskusi dan komunikasi dengan Ketua MGMP Kimia SMA. Informasi yang diperoleh dari Ketua MGMP ini (diperoleh dari "keluhan" atau "pertanyaan" dari para guru) juga digunakan sebagai dasar dan pertimbangan dalam penyusunan dan pengembangan angket. Dari hasil kesemuanya ini tersusun Instrumen Asesmen tentang STEM.

Pertanyaan dalam instrumen asesemen disusun dengan jenis Selected Repond Items (Tes berbentuk objektif) sebanyak 11 butir. Di samping itu dikembangkan Angket untuk memperoleh masukan peserta tentang Program Kegiatan Pengabdian kepada Masyarakat ini. Angket yang dikembangkan terdiri dari 10 butir parameter dalam bentuk selected response item dan 1 butir dalam bentuk constructed response item (komentar dan saran/masukan).

\section{Hasil yang dicapai pada Tahap Pelaksanaan}

Pelaksanaan kegiatan tahap 1 selama satu hari yaitu pada hari Sabtu tanggal 8 Agustus bertempat di SMA Negeri 1 Madiun. Peserta adalah guru-guru kimia yang tergabung pada forum MGMP Kimia SMA dan SMK di Kota Madiun. Kegiatan diikuti oleh 21 orang guru dari sebanyak 25 orang guru yang menjadi target. Pada saat pembukaan di hari pertama dihadiri dan dibuka oleh Ketua MGMP Kimia Kota Madiun. kegiatan tersebut ditunjukkan pada Gambar 3.

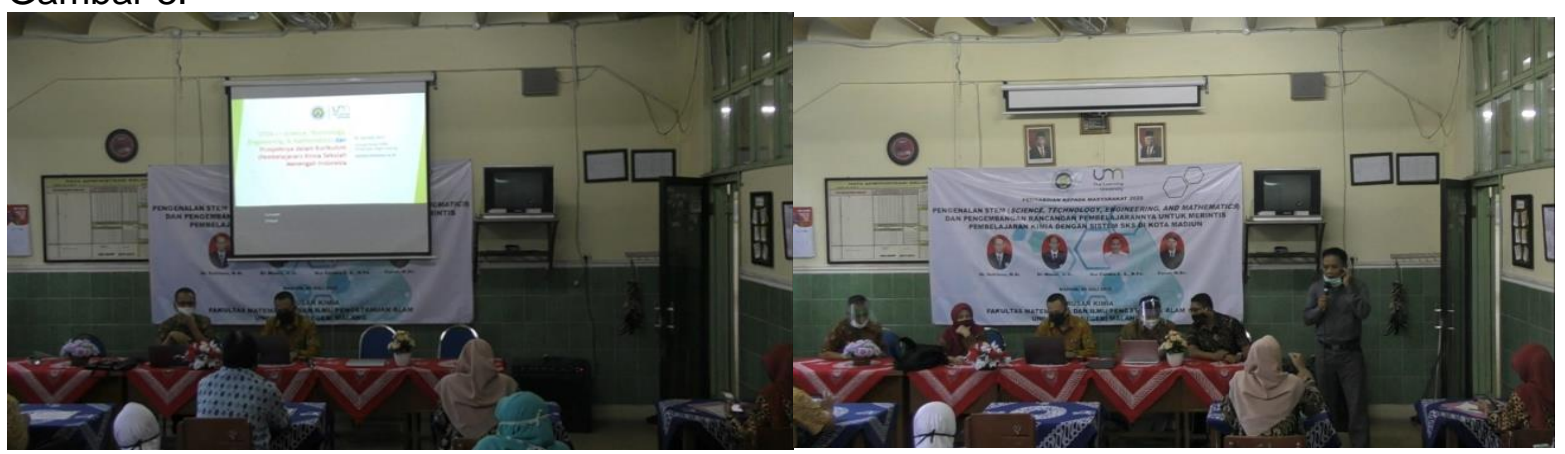

Gambar 3. Pelaksaan Pembukan dan workshop 
Kegiatan dapat berlangsung dengan baik sesuai dengan perencaan keseluruhan peserta mengikuti program ini dengan tekun, semangat, dan penuh perhatian, yang ditandai dengan "suasana hidup" melalui tanya-jawab dan diskusi. 70\% dari jumlah peserta memberikan tanggapan dan pertanyaan terkait dengan materi yang disampaikan seperti konsep-konsep kimia yang dapat diaplikasikan dengan rancangan STEM. Ini menunjukkan bahwa peserta memiliki keinginan kuat untuk mendalami STEM sebagai perangkat dalam mengajarkan kimia ke siswa disekolah.

Peningkatan kompetensi guru dalam memahami STEM sebagai bagian dari pembelajaran kimia diukur menggunakan tes yang diberikan melalui google form. Pemberian tes dilakukan sebelum memulai kegiatan (pre-test) dan sesudah selesai kegiatan (post-test). Adapun proses pelaksanaan pre-test dan post-testseperti yang ditampilkan pada Gambar 4 berikut.

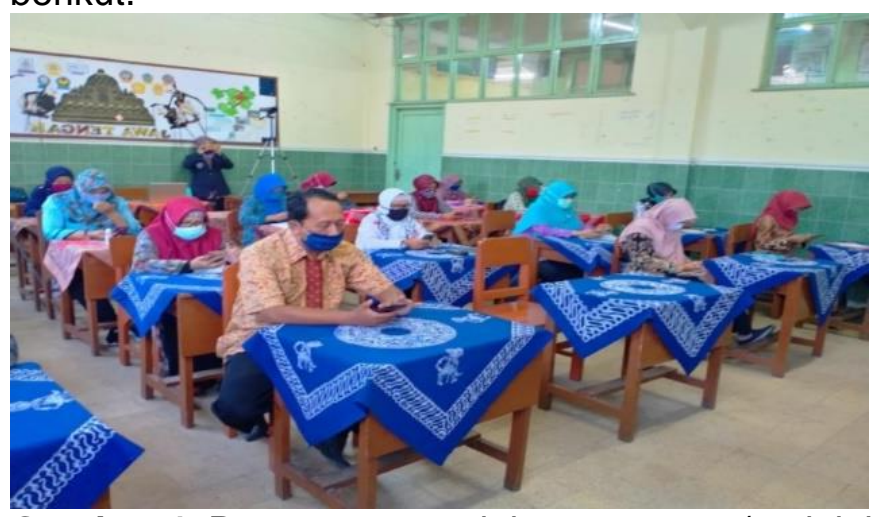

Gambar 4. Peserta mengerjakan post-test (melalui Google form)

Hasil tabulasi dan analisi pre test dan Postes disajikan pada Tabel 2 sebagai berikut. Tabel 2. Analisis peningkatan pemahaman STEM

\begin{tabular}{rlrrr}
\hline \multirow{2}{*}{ No } & Kategori & Pre-Test & Post-Test & \multicolumn{2}{c}{$\begin{array}{c}\text { rata-rata } \\
\text { Peningkatan }\end{array}$} \\
\cline { 3 - 4 } & Senar & \multicolumn{1}{c}{ Benar } & 100 & 0 \\
2 & Singkatan dari STEM & 9.1 & 100 & 90.9 \\
3 & STEM merupakan sebuah atau suatu & ide tentang & 100 & 40.9 \\
4 & Negara pencetus ide lahirnya STEM & 59.1 & 38.1 & 19.9 \\
5 & Fokus atau penekanan Ide tentang & 18.2 & 71.4 & 8.7 \\
6 & STEM & 62.7 & 100 & 9.1 \\
7 & Katasan atau definisi STEM & 90.9 & & 40.7 \\
8 & Karakteristik tentang sains (science) & 54.5 & 95.2 & 13.6 \\
9 & Karaktau definisi ringkas & & & 100 \\
\hline
\end{tabular}

Berdasarkan tes awal (pre-test), rerata pemahaman tentang STEM adalah 56,3 dan setelah kegiatan 82,5, atau terjadi peningkatan rata-rata sebesar 25.7. Hal ini menunjukkan bahwa kegiatan ini berdampak pada peningkatan kemampuan atau kompetensi guru dari sisi penguasaan pemahaman STEM. Kegiatan ini mampu "lebih menghomogenkan" penguasaan STEM para guru kimia di Kota Madiun. Pemahaman guru tentang STEM dapat berdampak pada proses pembelajaran kimia yang lebih baik dan epektif. STEM adalah cara berpikir tentang bagaimana pendidik di semua tingkatan termasuk orang tua harus membantu siswa mengintegrasikan pengetahuan lintas disiplin, mendorong mereka untuk berpikir dengan cara yang lebih terhubung dan holistik (Sneideman, 2013). 
Indonesia perlu mengembangkan pendidikan berbasis STEM. Memasuki pendidikan STEM harus dipersiapkan secara matang khususnya bagi guru agar proses pembelajaran dan penerapan kurikulum 2013 dapat berjalan dengan baik. Kemampuan guru dalam menerapkan STEM dalam pembelajaran kimia diharapkan akan berdampak pada pembiasaan siswa dalam berpikir kritis, berinovasi dan mampu memecahkan masalah (Zubaidah, 2017). Pembelajaran STEM untuk peserta didik diharapkan mereka mampu berinovasi, kolaborasi, dan bertahan dalam permasalahan sehari-hari (Soylu, 2016).

Respon guru terhadap kegitan PKM diinput menggunakan instrumen angket. Adapun hasil angket dijabarkan sebagai berikut.

Apakah kegiatan ini benar-benar bermanfaat untuk tugas dan (pengembangan) karir bapak/ibu sebagai guru? (100\%)

1. Apakah bapak/ibu memperoleh pengetahuan baru dari kegiatan ini, khususnya tentang sumber belajar, bahan ajar, dan modul? (100\%)

2. Apakah bapak/ibu merasa memperoleh tambahan atau pendalaman konsep-konsep dalam bidang studi dan pengembangang modul? $(\mathrm{Ya}=93 \%$, Ragu $=7 \%$ )

3. Apakah strategi atau model yang digunakan dalam kegiatan ini, bapak/ibu merasa selaras atau sesuai dengan tuntutan/harapan yang $b$ ? $(\mathrm{Ya}=96 \%$, Ragu $=4 \%)$

4. Secara umum, saya bisa menerima secara komprehensif dari materi yang telah disampaikan dalam kegiatan ini. ( $\mathrm{Ya}=89 \%$, Tidak $=5 \%$, Ragu $=6 \%$ )

5. Melalui kegiatan ini saya memahami secara utuh tentang STEM. (Ya $=75 \%$, Biasa saja $/$ Ragu $=20 \%$, dan Tidak $=5 \%$ )

6. Saya BISA menyusun pembelajaran kimia di sekolah dengan STEM. $(\mathrm{Ya}=65 \%$, Ragu $=$ $30 \%$, dan Tidak $=5 \%$ )

7. Apakah kegiatan semacam ini perlu dilakukan secara periodik? $(\mathrm{Ya}=93 \%$, Tidak menjawab $=7 \%$ )

Sebagai upaya meningkatkan kualitas program yang dilaksanakan melalui PKM tim meminta peserta untuk memberikan komentar, saran atau harapan terakiat dengan kegitan yang telah dilakukan. Adapun hasil disajikan pada Tabel 3 berikut.

Tabel 3. Komentar, Saran, dan/atau Harapan sehubungan dengan Pelaksanaan Kegiatan Pengabdian

\begin{tabular}{|c|c|}
\hline Komentar, Saran, dan/atau Harapan & $\begin{array}{l}\text { Jumlah } \\
\text { Responden } \\
(\%)\end{array}$ \\
\hline $\begin{array}{l}\text { 1. Sangat mengaharapkan kegiatan ini dilaksanakan secara periodik } \\
\text { (berlanjut) sehingga bisa memperoleh ilmu-ilmu yang baru dan bisa } \\
\text { sharing dalam hal pembelajaran, meningkatkan kompetensi guru, } \\
\text { menambah wawasan guru untuk menemukan solusi dari } \\
\text { permasalahan pembelajaran yang dialami }\end{array}$ & 66 \\
\hline 2. Semoga dari pelatihan ini kami bisa menambah pengetahuan & 29 \\
\hline $\begin{array}{l}\text { 3. Waktu pelaksanaan hendaknya lebih lama dan dilakukan secara } \\
\text { periodik }\end{array}$ & 34 \\
\hline $\begin{array}{l}\text { 4. Kegiatan pelatihan dan pendampingan ini sangat membantu guru } \\
\text { kimia dalam memilih, merencanakan, dan mengaplikasikan model } \\
\text { pembelajaran, untuk PTK }\end{array}$ & 46 \\
\hline 5. Diadakan kegiatan lanjutan & 6 \\
\hline $\begin{array}{l}\text { 6. Lebih banyak lagi konsep-konsep kimia yang lebih mudah diajarkan } \\
\text { ke guru untuk kemudian diberikan atau ditransfer ke siswa }\end{array}$ & 86 \\
\hline $\begin{array}{l}\text { 7. Penyelenggaraan workshop ini harusnya lebih dari } 1 \text { hari (waktu } \\
\text { disesuaikan dengan materi yang disampaikan) agar hasil yang } \\
\text { diperoleh maksimal, lebih banyak tuntutan praktik/tugas dan } \\
\text { bimbingan }\end{array}$ & 9 \\
\hline $\begin{array}{l}\text { 8. Semoga tetap ada komunikasi efektif dan membawa dampak positif } \\
\text { baqi guru dan dosen }\end{array}$ & 14 \\
\hline
\end{tabular}

Kegiatan pendidikan dan pelatihan dalam rangka penguatan implementasi Kurikulum 2013 dapat meningkatkan penguasaan pemahaman atau penguasaan konsep bidang studi 
dan pembelajaran kimia bagi para guru kimia, khususnya di Kota Madiun. Peningkatan penguasaan konsep bidang pembelajaran lebih baik dibanding peningkatan penguasaan konsep bidang ilmu kimia. Hasil dan temuan kegiatan pendidikan dan latihan ini direkomendasikan untuk menjadi kegiatan yang bersifat periodik dan berkelanjutan hingga diperoleh atau dihasilkan guru yang profesional. Melalui kegiatan periodik diharapkan mampu menciptakan karakter pengembangan keprofesionalan berkelanjutan dari para guru, khususnya guru kimia di sekolah menengah.

\section{KESIMPULAN}

Program Kemitraan Masyarakat mampu menjadi solusi atas permasalahan yang dihadapi guru kimia di Kota Madiun, ditunjukkan oleh peningkatan capaian pembelajaran melalui diklat sebesar $43,1 \%$, dapat meningkatkan pemahaman guru kimia di Kota Madiun tentang STEM sebesar $26,35 \%$, guru peserta diklat dan pendampingan di Kota Madiun mempunyai wawasan dan pemahaman yang lebih baik tentang STEM, dan guru memiliki keteramilan yang baik dalam menyusun rancangan pembelajaran berbasis STEM untuk diaplikasikan disekolah masing-masing peserta.

\section{REKOMENDASI}

Kegiatan PKM menjadi bagian usaha akademik dosen untuk membina masyarakat yang memiliki persoalan-persoalan yang belum bisa dipecahkan. Kegiatan PKM yang telah dilakukan yakni Pengenalan STEM dan Pengembangan Rancangan Pembelajarannya Untuk Merintis Pembelajaran Kimia Dengan Sistem SKS Di Kota Madiun. Masih perlu dilakukan secara kontinu agar guru benar-benar dapat mengembangakan perangkat pembelajaran berbasis STEM dengan mandiri.

\section{DAFTAR PUSTAKA}

Agustina, D., Kaniawati, I., \& Suwarma, I. R. (2017). Penerapan Pembelajaran Berbasis Stem (Science, Technology, Engineering And Mathematics) Untuk Meningkatkan Kemampuan Control Of Variable Siswa Smp Pada Hukum Pascal. PROSIDING SEMINAR NASIONAL FISIKA (E-JOURNAL) SNF2017 UNJ, SNF2017-EER-35SNF2017-EER-40. https://doi.org/10.21009/03.SNF2017.01.EER.06

Ardianto, D., Firman, H., Permanasari, A., \& Ramalis, T. R. (2019). What is Science, Technology, Engineering, Mathematics (STEM) Literacy? Proceedings of the 3rd Asian Education Symposium (AES 2018). Proceedings of the 3rd Asian Education Symposium (AES 2018), Bandung, Indonesia. https://doi.org/10.2991/aes-18.2019.86

Hanover Research. (2011). K-12 STEM Education Overview. hanoverresearch.com

Kumano, Y., \& Goto, M. (2015). Issues Concerning Scientific Processes in Science Lessns Involving Outdoor and Indoor Activities: A Comparative Study of Scientific Processes in Japanese Science Classes and the Cronological Development of Scientific Processes in the US through NGSS. Paper presented in USA, held in January, 2015.

Matanluk, O., Mohammad, B., Kiflee, Dg. N. Ag., \& Imbug, M. (2013). The Effectiveness of Using Teaching Module based on Radical Constructivism toward Students Learning Process. Procedia - Social and Behavioral Sciences, 90, 607-615. https://doi.org/10.1016/j.sbspro.2013.07.132

Mulyani, T. (2019). Pendekatan Pembelajaran STEM untuk menghadapi Revolusi Industry 4.0. Prosiding Seminar Nasional Pascasarjana (PROSNAMPAS), 2(1), 453-460.

Rustaman, N., Y. (2015). STEM EDUCATION: How to integrate STEM Education into Biology subject-matter? Seminar Nasional Universitas Negeri Yogyakarta (UNY), Yogyakarta.

Sneideman, J., M. (2013, December 18). Engaging Children in STEM Education Early! Natural Start. https://naturalstart.org/feature-stories/engaging-children-stem-education-early

Soylu, S. (2016). STEM Education In Early Childhood In Turkey. Journal Of Educational And Instructional Studies In The World, 6(1), 38-47.

Susanti, L. Y. (2018). Penerapan Media Pembelajaran Kimia Berbasis Science, Technology, Engineering, And Mathematics (Stem) Untuk Meningkatkan Hasil Belajar Siswa Sma/ Smk Pada Materi Reaksi Redoks. Jurnal Pendidikan Sains (JPS), 6(2), 32. https://doi.org/10.26714/jps.6.2.2018.32-40 
Torlakson, T. (2014). INNOVATE: ABlueprint for Science, Technology, Engineering, and Mathematics in California Public Education. California Departement of Education.

Zubaidah, N. (2017, August 1). Indonesia Perlu Mengembangkan Pendidikan Berbasis STEM. SINDOnews.com. https://edukasi.sindonews.com/berita/1226155/144/indonesia-perlumengembangkan-pendidikan-berbasis-stem 